is a Predoctoral Research Fellow, Division of General Medical Sciences, U.S. Public Health Service. M.A.C. is a Research Career Development Awardee, U.S. Public Health Service.

Department of Biochemistry, MARY M. EICHHORN Tufts University School of Medicine, MORRIS A. CYNKIN Boston, Mass. (U.S.A.)

${ }^{1}$ F. B. Cramer and G. E. Woodward, J. Franklin Inst., 253 (I952) 354.

2 A. N. Wick, D. R. Drury, H. I. Nakada and J. B. Wolfe, J. Biol. Chem., 224 (1957) 963.

3 A. K. Williams and R. G. EAGON, J. Bacteriol., 77 (I959) I67.

4 E. R. Blakley and O. Ciferri, Can. J. Microbiol., 5 (1961) 6I.

${ }^{5}$ N. Nelson, $J$. Biol. Chem., I 53 (1944) 375.

B S. Hestrin, J. Biol. Chem., I80 (1949) 249.

7 S. A. Brooks, J. C. LAWRENCE AND C. R. RicketTs, Nature, I87 (I960) 1028.

${ }^{8}$ M. M. Eichiorn and M. A. Cynkin, Am. Chem. Soc. Abstr. (5-C), September 1963.

Received October 25th, I963

Biochim. Biophys. Acta, 82 (1964) 204-207

\title{
Catabolism of $\gamma$-hydroxy[2-14 C]glutamic acid by excised leaves of Phlox decussata
}

PN I332

The mammalian metabolism of $\gamma$-hydroxyglutamate, an intermediate in hydroxyproline catabolism ${ }^{\mathbf{1}, 2}$, has recently been described in considerable detail ${ }^{\mathbf{3}-10}$. Studies in our laboratory have shown that enzymes present in rat-liver extracts catalyze the net formation of glyoxylate and alanine from $\gamma$-hydroxyglutamate by the following sequence of reactions ${ }^{6,11}$ :

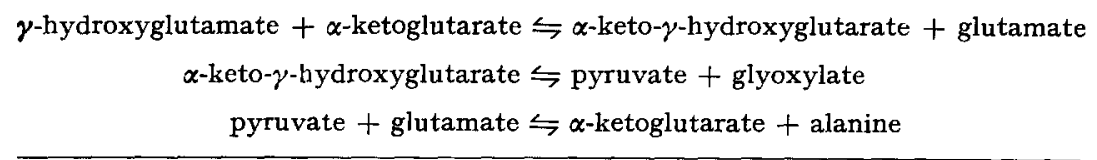

Net reaction: $\gamma$-hydroxyglutamate $\leftrightharpoons$ glyoxylate + alanine

No information is available, however, concerning the synthesis and breakdown of this amino acid by Phlox decussata, the plant in which it was originally discovered ${ }^{12}$ and where it occurs as a major constituent of the soluble nitrogen fraction of the leaf ${ }^{13}$. In experiments designed to study the formation of $\gamma$-hydroxyglutamate in Phlox, other investigators ${ }^{\mathbf{1 4}, 15}$ detected no assimilation of isotope into $\gamma$-hydroxyglutamate after administering ${ }^{14} \mathrm{CO}_{2}$ and $\left[2-{ }^{14} \mathrm{C}\right]$ pyruvate to the plant. The suggestion has been made, therefore, that the compound might represent only a storage product. These findings led us to examine the possibility of whether or not the plant is able to degrade $\gamma$-hydroxyglutamate.

The $\gamma$-hydroxy $\left[2{ }^{14} \mathrm{C}\right]$ glutamate used in these studies was synthesized by the method of BeNOITON AND BouthillieR ${ }^{3}$ (specific activity $=103000$ counts $/ \mathrm{min}$ per $\mu$ mole). The compound migrated on one- and two-dimensional chromatograms 
as a homogeneous substance with the mobility of authentic $\gamma$-hydroxyglutamate. On radioautographs, a single radioactive spot coincided with the ninhydrin-positive spot.

Phlox decussata, var. Firebrand, was grown in the greenhouse from roots purchased commercially. When the plants were 2 months old, leaves were cut off at the base of the petiole and immediately placed in a neutral solution containing 389000 counts/min of $\gamma$-hydroxy $\left[2-{ }^{14} \mathrm{C}\right]$ glutamate. Four young leaves were used per experiment and the labeled compound was assimilated in the light for periods of 6 , I2, and $24 \mathrm{~h}$. Distilled, deionized water was added as needed to prevent wilting of the leaves.

At the end of the experimental period, the leaves were leached with boiling $70 \%$ ethanol. The resulting green solution was extracted with Skellysolve B (technical hexane) to remove lipids and pigments, and the ethanol layer was concentrated in vacuo to a small volume. After this solution was neutralized with $\mathrm{KOH}$, the amino acids were adsorbed on a column of Dowex $-50\left(\mathrm{H}^{+}\right.$phase $)$resin and, after thorough washing with water, were subsequently eluted with aqueous ammonia. The eluate containing the amino acids was concentrated to dryness in vacuo to remove ammonia and then dissolved in $\mathrm{I} \mathrm{ml}$ of $\mathrm{H}_{2} \mathrm{O}$. The amino acids present in duplicate aliquots of each sample were separated by two-dimensional chromatography on large sheets of Whatman No. I paper. The solvents used were tert-amyl alcohol-formic acid-water $(6: 2: 2, v / v)$ followed by $m$-cresol-phenol $(2: \mathrm{I}, \mathrm{v} / \mathrm{w})$, o.I M borate buffer $(\mathrm{pH} 8.3)$.

Radioactive compounds, located on the air-dried chromatograms by radioautography, were washed from the paper with water. Aliquots of the concentrated eluates were assayed for radioactivity by counting infinitely thin samples with a thin-window gas-flow counter. Amino acids were determined quantitatively by the method of $\operatorname{RosEN}^{16}$.

Table I shows that administering $\gamma$-hydroxy $\left[2-{ }^{14} \mathrm{C}\right]$ glutamate to Phlox leaves results in considerable degradation of the compound with subsequent incorporation of radioactivity into amino acids as well as other substances (neutral and anionic). The $\gamma$-hydroxyglutamate applied to the leaves was a mixture of all four possible isomers, of which two (the L-isomers) or possibly only one (the threo-L-isomer ${ }^{13}$ ) is metabolically active. This must be considered when evaluating the extent of isotope incorporated into other compounds.

The specific activities of individual radioactive amino acids formed in these experiments are listed in Table II. Two unknown weakly ninhydrin-positive compounds also contained a small amount of radioactivity, but the specific activities could not

TABLE I

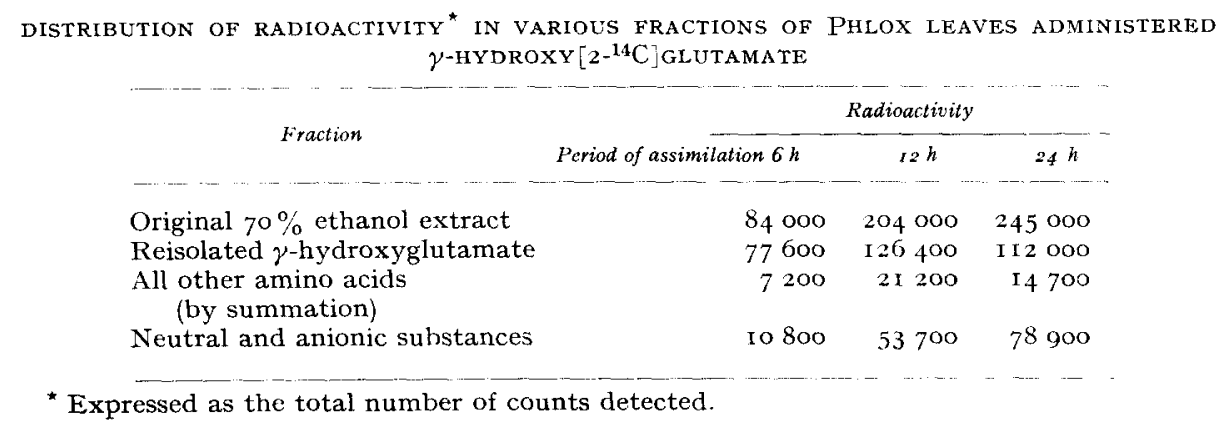


TABLE II

average SPECIfic activity ${ }^{\star}$ of amino acids isolated from Phlox leaves administered $\gamma$-HYDROXY $\left[2-{ }^{14} \mathrm{C}\right]$ GLUTAMATE

\begin{tabular}{lrrr} 
& & \multicolumn{3}{c}{ Specific activity } \\
\cline { 2 - 3 } \multicolumn{1}{c}{ Amino acid } & Period of assimilation $6 h$ & $12 h$ & $24 h$ \\
\hline & & & \\
$\gamma$-Hydroxyglutamic acid & 2470 & 3990 & 3370 \\
Aspartic acid & 330 & 360 & 200 \\
Glutamic acid & 350 & 570 & 440 \\
Serine & 160 & 290 & 120 \\
Alanine & 680 & 1360 & 590 \\
& & &
\end{tabular}

* Expressed as counts $/ \mathrm{min} / \mu$ mole of amino acid, corrected for losses due to chromatography.

be determined. The apparent increase in specific activity shown for $\gamma$-hydroxyglutamate is very likely the result of the experimental conditions; continued uptake of the radioactive compound into a large intracellular pool could take place throughout the experiment. In actuality, the per cent of radioactivity present as $\gamma$-hydroxyglutamate dropped with time. In all of our experiments, alanine showed the highest specific activity. This finding suggests that $\gamma$-hydroxyglutamate may be metabolized by the plant via pathways analogous to those already described for the mammal. In preliminary experiments, crude homogenates of $P$. decussata leaves have failed to convert $\gamma$-hydroxyglutamate to glyoxylate and alanine. However, VIRTANEN AND Hietal ${ }^{17}$ demonstrated that Phlox-leaf homogenates catalyze a transamination between $\gamma$-hydroxyglutamate and $\alpha$-ketoglutarate, a reaction now known to be the first catabolic step of $\gamma$-hydroxyglutamate in mammals. Studies on the metabolism of $\gamma$-hydroxyglutamate by $P$. decussata are being continued.

We wish to thank Dr. A. G. Norman for providing space and facilities in the University of Michigan Botanical Gardens for growing Phlox decussata. This work was supported in part by a grant from the U.S. Public Health Service (Grant AM-37I8).

\section{The University of Michigan, Department of Biological Chemistry, ALMA D. Homola Ann Arbor, Mich. (U.S.A.)

1 E. Adams and A. Goldstone, J. Biol. Chem., 235 (1960) 3492.

2 E. Adams and A. Goldstone, J. Biol. Chem., 235 (1960) 3504.

3 L. Benoiton and L. P. Bouthillier, Can. J. Biochem. Physiol., 34 (1956) 66I.

4 K. Kuratomi and K. Fukunaga, Biochim. Biophys. Acta, 43 (1960) 562.

5 U. Maitra and E. E. Dekker, Biochim. Biophys. Acta, 5 I (I96I) 4 I6.

6 E. E. Dekker and U. Maitra, J. Biol. Chem., 237 (I962) 2218.

7 L. P. Bouthillier, Y. Binette and G. Pouliot, Can. J. Biochem. Physiol., 39 (196i) i 595.

${ }^{8}$ L. P. Bouthillier and Y. Binette, Can. J. Biochem. Physiol., 39 (196r) r93o.

- U. Maitra and E. E. Dekker, Federation Proc., 2 I (I962) 4.

10 A. Goldstone and E. Adams, J. Biol. Chem., 237 (I962) 3476.

11 U. Maitra and E. E. DekKer, J. Biol. Chem., 238 (I963) 3660.

12 A. I. Virtanen and P. K. Hietala, Acta Chem. Scand., 9 (I955) I 75.

13 E. E. DeKker, Biochem. Prep., 9 (1962) 69.

14 G. E. Hunt, Plant Physiol., 33 (1958) s!ıpl. xi:.

15 P. Linko and A. I. Virtanen, Acta Chem. Scand., I 2 (1958) 68.

16 H. Rosen, Arch. Biochem. Biophys., 67 (1957) ro.

17 A. I. Virtanen and P. K. Hietala, Acta Chem. Scand., 9 (I955) 549.

Received November 5 th, I963 